\title{
Planning and undertaking asbestos surveys of social housing
}

Received (in revised form): 4th April, 2005

\section{Stephen Cooper MCIOB}

is a chartered building surveyor and Managing Director of PHH Environmental (UK) Ltd. He has worked in housing for most of the last 35 years. From 1981 to 2004 he worked in social housing, spending much of this time being concerned with building pathology and asset management. During the early 1990s, he produced seminal work on stock condition surveys and component coding structures for social housing in Wales. He has worked for housing associations, care home providers and the government regulator of housing associations. Stephen now manages PHH Environmental (UK) Ltd, which specialises in asbestos management and is currently working extensively in social housing.

\begin{abstract}
The purpose of this paper is to help inform social housing providers (SHPs) and their surveyors and managers of the key issues that determine the need for, and arise from, planning and undertaking asbestos surveys of social housing. This paper discusses some of the practical problems and issues concerning asbestos and the management of social housing. The position of asbestos within the Decent Homes Standard and the forthcoming new fitness test for social housing, the Housing Health \& Safety Rating System (HHSRS) introduced in the Housing Act of 2004, are discussed.
\end{abstract}

\section{Keywords:}

asbestos surveys, asbestos management plans, health and safety, social housing

\section{INTRODUCTION}

Following on from the paper in the last issue of the Journal of Building Appraisal entitled: 'Managing asbestos risk' by Daniel Jude (2005), this paper looks at some of the issues raised in relation to social housing providers (SHPs).

Many SHPs have now carried out asbestos surveys of the communal areas within their housing stock to satisfy the specific legal requirement under Regulation 4 of the Control of Asbestos at Work Regulations 2002 (CAWR, 2002), which came into force in May 2004. The survey data collected have allowed SHPs to produce asbestos registers detailing where asbestos can be found with information about its type and nature. In many

Stephen Cooper Managing Director PHH Environmental (UK) Ltd 3 Cwrt-y-Parc, Earlswood Road Cardiff, CF14 5GH, UK

Tel: +44 (o) 2920747441

Fax: + 44 (o)2920 747442

E-mail: scooper@phhenv.co.uk cases, however, this information has not been integrated with general stock condition survey data and may not be readily accessible to contractors carrying out work on a property. In order to meet the legislation, SHPs have produced asbestos management plans (AMPs) to detail how they will deal with the asbestos risk. Such management plans should be the basis of an on-going management strategy. 

SHPs have a duty of
care re. asbestos

\section{Guidance available concerning asbestos}

Inevitably, different SHPs will interpret their responsibilities differently and will also adopt individual strategies to deal with their general duty of care to employees working in a property that may involve asbestoscontaining materials (ACMs). Strategies will be impacted upon by the property profile of the SHP and their ability to finance the work.

\section{WHY SHOULD SHPS BE CONCERNED WITH ASBESTOS?}

SHPs have a duty of care to protect tenants and employees from health and safety risks associated with ACMs (Jude, 2005). Does Regulation 4 of CAWR 2002 apply to housing? Yes, it is clear that Regulation 4 applies to common parts of housing. This is clarified in the Health \& Safety Executive (HSE) Approved Code of Practice (ACOP) L127 (HSE, 2002a). ACOP L127 states that Regulation 4 of CAWR 2002 (HMSO, 2004: para. 7) applies to common parts of domestic rented premises, such as hallways, stairs, lifts, yards and outhouses. It goes on to say that this does not apply to kitchens and bathrooms etc in shared houses and communal lounges in sheltered accommodation. SHPs have to be particularly careful in this instance as many shared houses are used for tenants with special needs and consequently staff may work within the premises. Staff also may be employed at sheltered accommodation. In such cases it would be prudent to assume that health and safety legislation will apply as employees use the premises as their normal place of work. It would seem reasonable then, under this general duty of care, to include such properties in the SHP's asbestos survey programme.

For major repairs and improvement programmes it is clearly the client's responsibility to inform the principal contractor of any asbestos risks under the Construction (Design \& Management) Regulations 1994 (HMSO, 1994).

In response to the above, many SHPs are considering arranging asbestos awareness training for their contractors. SHPs need to satisfy themselves that their contractors are properly trained to deal with any ACMs and know how to carry out small repairs that may impact on ACMs. Good guidance on this is provided in two HSE guides, HSG213: Introduction to Asbestos Essentials (HSE, 2001a) and HSG210: Asbestos Essential Task Manual (HSE, 2003). The Task Manual gives good practical guidance on carrying out minor repairs that affect ACMs, such as 'drilling holes in asbestos insulating board' (HSE, 2003).

At the Institution of Occupational Safety and Health annual conference on 28th April, 2005, Dr Kevin Walkin, Head of the HSE Asbestos Unit, announced that as part of the further campaign of the HSE, the HSE had government approval to look at the possibility of the extension of Reg. 4 under CAWR2002 to include certain rented domestic property.

\section{SPECIFIC GUIDANCE TO SHPS}

A guidance publication entitled: Managing Asbestos in Social Housing (2004) has been produced for SHPs in Wales by an Asbestos Working Group under the auspices of the Welsh Local Government Association, the Welsh Federation of Housing Associations and the Welsh Assembly 


\section{Informing tenants}

\section{Survey types}

Government. This document draws attention to the need for consideration of the general duty of care to maintenance workers and risks to tenants.

The National Housing Federation (2004) has published an 'asset management' newsletter on asbestos, which gives general guidance. This document advocates a proportionate approach. While noting that a full survey may not be necessary in all cases, it clearly states that an SHP should assume that all materials being worked on are asbestos until a proper assessment has been undertaken.

The need for a stock condition survey that takes asbestos into account and the subsequent creation of an asbestos register is highlighted in the Housing Quality Network Services Housing Corporation (2003) publication Inspection Uncovered.

\section{WHAT DO SHPS TELL THEIR TENANTS?}

Asbestos can be an emotive issue and the SHP's policy needs to be carefully communicated to tenants. Surveys have been carried out without properly informing tenants, where surveyors are advised to tell tenants that they are surveying general building materials. Many tenants respond to this with, 'come on, we're not stupid, you're surveying for asbestos aren't you?'. This sort of approach may be counterproductive and generate mistrust.

Once SHPs have decided on their policy in relation to asbestos and tenants they should check with their insurers. Insurers will have a view and SHPs would be ill-advised to adopt a policy that may jeopardise their insurance cover in the event of a claim made by a tenant.

Effective communication and consultation with residents at an early stage in major repair programmes where ACMs are identified is important. It is easy for the risks to be misrepresented by uninformed individuals either concerned for their safety or in consideration of perceived potential compensation.

An open and honest approach is advocated. Some SHPs have produced useful initial information items in their newsletters followed up by more detailed guidance. The best communication is where concerns are preempted with appropriate responses. Tenants should be advised that a survey is being completed to meet legislation and to improve tenant safety. Consideration should be given to holding a local 'surgery' to communicate findings and respond to questions.

\section{WHAT TYPE OF SURVEY IS NEEDED?}

The survey types are defined in MDHS 100: Surveying, Sampling and Assessment of Asbestos-containing Materials, published by the HSE (2001b). Type 1 surveys do not include sampling of suspect ACMs and subsequent analysis by a laboratory accredited to ISO 17025 . While useful in some cases as an initial step, to get an idea of the scale of the issue, Type 1 surveys are of limited value due to their presumptive nature. Any incidence of potential ACMs will be presumed to be positive. This can lead to significantly increased costs if relied upon for proposed maintenance work etc. An initial sample Type 1 survey may be used as a first step to inform and allow accurate planning of a full Type 2 survey. 
Type 2 surveys, where suspect ACMs are sampled and analysed, are the most appropriate in occupied property. These give an accurate picture of the scale and incidence of ACMs.

Type 3 surveys are applicable where maintenance, renovation or demolition work is proposed. In Type 3 surveys, attempts are made to discover concealed or covered ACMs that may be exposed during the proposed works. These surveys are essentially the same as Type 2 surveys except they do create some damage as they are intrusive or destructive and are not normally carried out in occupied property.

Survey reports should include drawings to allow sample reference points and ACMs to be located within the building. Many survey reports now also include digital photographs.

There can be significant delays between determining that an asbestos survey is required and receiving the completed asbestos register and management plan. Such a delay may be partially due to the volume of work being undertaken by qualified asbestos surveyors, which has inevitably created a market into which existing consultants can diversify. Care should be taken in selecting consultants to confirm their suitability. They should have surveyors with both building construction experience and qualifications to the proficiency certificate level in building surveys and bulk sampling for asbestos (module P402), which is managed by the British Occupational Hygiene Society, Faculty of Occupational Hygiene. ${ }^{1}$ SHPs are encouraged to consider using consultants registered with Constructionline, ${ }^{2}$ the UK's register of local and national construction and construction-related contractors and consultants, pre-qualified to work within the public sector. The SHP should also confirm that the consultant has appropriate professional indemnity insurance specifically for asbestos surveying. The perceived risks associated with failure of an asbestos survey may be significantly greater than those relevant to general building surveys.

ACM products that can be found in housing
WHAT SORT OF ACMS MIGHT BE FOUND IN SOCIAL HOUSING?

The following are some of the more common occurrences of asbestos in housing.

- Decorative textured coatings such as 'Artex' and 'Nutex'

- Asbestos cement and asbestos insulation board soffits to fascia, undercloak to verges and porch ceilings

- Asbestos cement flue pipes

- Asbestos cement rainwater goods

- Asbestos cement bath panels

- Asbestos cement toilet cisterns and water header tanks

- Resin toilet cisterns

- Asbestos insulation board or asbestos cement boxing to soil and vent pipes etc

- Asbestos insulation board to airing cupboards, behind or above cooker spaces and meter boxes 
- Vinyl floor tiles and adhesive (in some cases the adhesive may be an ACM and the tile may be asbestos free)

- Sarking or underfelt to roof coverings

- Bitumen sink pads to stainless steel sink tops.

Notwithstanding the above, a wide range of ACM products can be found in housing. Ex-local authority housing can also include a proportion of nonstandard or 'system built' housing, which may include ACMs in less common locations. For example, in steel frame housing, flues to lounge fires are often constructed in steel with asbestos insulation in pre-formed sections.

'Artex' is a particularly difficult material for SHPs to deal with for a number of reasons. In some stock it may be common and introduced at varying periods by tenants. 'Artex' from room to room may be of a different visual appearance or pattern and this will require extensive sampling. It is not a particularly homogeneous material requiring a careful sampling strategy to ensure it is properly assessed. While 'Artex' is a relatively low-risk product it is currently a licensed product under the Asbestos (Licensing) Regulations 1983 (HMSO, 1998), although this will be reviewed in the future according to HSE sources.

\section{Prioritising ACMs}

\section{HOW SHOULD ACMs BE PRIORITISED?}

Based on the information collected as part of the asbestos survey, an AMP should be developed and introduced to deal with the ACMs. This will be based on a material and priority risk assessment. Most ACMs present no risk until disturbed so asbestos management is about predicting component disturbance and pre-emptively planning for it. Good guidance on this is available in the HSE publication HSG227: A Comprehensive Guide to Managing Asbestos in Premises (HSE, 2002b). If the AMP is produced by an external organisation it may be in draft form. Prior to the SHP adopting the draft AMP it will need careful consideration and consultation to ensure that reasonable assumptions have been made to inform the scoring to create the priority ratings.

ACMs either must be labelled to identify them or a robust 'permit to work' system must be adopted. This may be a difficult area for SHPs; if the ACM is identified within a tenant's home, labelling may be considered inappropriate. Alternatively, a 'permit to work' system may be difficult to enforce, especially in relation to minor works carried out by tenants such as putting a shelf up or removing 'Artex' as part of decorating. SHPs have adopted a range of strategies to deal with this, with many opting for a mix of a robust permission to work procedure based on their existing works order system with some labelling in communal areas and good information to tenants.

Once identified, ACMs not recommended for removal will need ongoing monitoring and management. Re-inspection should be carried out on a regular basis, at least annually. This is likely to be more frequent than an SHP's regular cycle of condition surveys. Therefore, SHPs will need to be able to manage the AMP actively. This generally will require the data to be held in digital format so that they can be interrogated, amended and manipulated. 


\section{Handling of data}

\section{Monitoring/managing vs removal}

\section{DATA HANDLING}

In some cases, the asset management (or component life cycle) software used by the SHP will accommodate or include an asbestos module, in others it will be in a stand-alone system. The data can be managed easily in a spreadsheet such as Microsoft Excel. The spreadsheet will contain the material type, description, location, quantity, material and priority risk scores, along with recommendations. The spreadsheet can be used to generate the algorithm that produces the risk scores. In some cases, SHPs are proposing to make the data accessible to out of hours contractors and emergency services as a searchable, web-based, password-protected database.

\section{TO REMOVE OR MANAGE IN SITU?}

Costs and disruption will be impacted by whether the ACM can be managed and monitored in situ or whether work or removal is required. Consideration must be given to any potential asbestos fibre release during disturbance of the ACM. In many cases, it is prudent to leave an ACM in situ, monitor and manage it. The decision to remove or manage in situ is dictated by the ACMs condition, likelihood of disturbance and the renovation plans for the property. An ACM in a poor condition in high traffic areas normally requires short-term removal.

If work or removal is required this will be further impacted by whether the work must be done by a licensed contractor or not. Specifically, asbestos cement products and certain bitumen, plastic, resin or rubber composite materials (where the thermal and acoustic properties are incidental to its main purpose), are not licensed products. Other insulation products which may be used at high temperatures but have no insulation purposes, such as gaskets, washers, ropes and seals, are also outside the licensing requirements. Care must be taken in identifying asbestos cement as it may be confused with asbestos insulation board, which is a licensed material. Asbestos cement is material that is predominately a mixture of cement and asbestos with a density in its dry state of $>1$ tonne per cubic metre. Details are given in the HSE publication: A Guide to the Asbestos (Licensing) Regulations 1983 (HSE, 1999).

Licensed work, such as removal of asbestos insulation board, will normally require the construction of an enclosure and such work is likely to cause a significant level of disturbance to residents, which may well necessitate decanting tenants on both health and disturbance grounds. Decanting will clearly significantly increase costs to the SHP.

In working on or removing ACMs, care must be taken to maintain any fire separation qualities that the ACM was used for. For example, in flats, service riser ducts are commonly constructed of asbestos insulation board to provide fire separation between floors. This may be difficult to identify in occupied flats as, in some cases, it may be clad with plywood. It is implicit in a Type 1 or 2 survey that screwed covers should be removed to allow inspection, however, if the boxing is fixed this will not be possible unless a Type 3 survey is undertaken.

It may be prudent in some cases to consider removal where the total costs of monitoring and managing the ACM during its life cycle will have 


\section{Asbestos and stock transfers}

Introduction of HHSRS a significant impact. SHPs should consider carrying out net present value (discounted cash flow) option appraisals of the alternatives of removal versus monitoring and managing. Direct overheads such as surveyor time should be fully costed. Increased maintenance costs and disturbance costs should be taken into account, along with an assessment of the less tangible costs of tenant liaison and any potential difficulty in letting or managing the property.

\section{ASBESTOS AND STOCK TRANSFERS}

Asbestos will be a significant consideration along with other environmental concerns for any Registered Social Landlord (RSL) receiving housing stock from a local authority as part of a stock transfer arrangement. Inevitably, the arrangement is likely to be partly influenced by the scope of environmental work and the ability of the receiving RSL to fund major repairs and improvements to the stock. Such work will require a full Type 3 survey of the stock concerned. While sample surveys can be used to establish a project budget they should not be relied upon as extrapolated data to other properties which have not been surveyed. Surveyors cannot extrapolate results to other properties that have not been surveyed as clearly ACMs may be present in locations where they were not in the sampled property. Plotting the incidence of ACMs using geographical information systems (GIS) can be a useful method of understanding the distribution of ACMs within the stock. Most local authority stock is of a sufficient age, however, to contain significant diversity from previous repairs and tenant-introduced changes (such as 'Artex'). Indeed, in the 1960s and 1970s, annual imports of ACMs peaked at over 150,000 tonnes per year (HSE, 2002a).

Department of the Environment Transport and the Regions (DETR) and The Housing Corporation (1999) mention asbestos in their publication:

Dealing with Uncertainty. The Role of Warranties in Stock Transfers. This document refers to widespread tipping half a century ago of asbestos waste slurry and sites previously used as asbestos factories but it does not refer to ACMs specifically within buildings. It goes on to mention that several RSLs have arranged specialist removal of undisclosed asbestos at their own expense rather than damage their relationship with the local authority.

Sample surveys are generally conducted of housing that is the subject of stock transfer, however, the information gathered is used specifically to inform the local authority and the valuation. This information may not be passed on to the receiving RSL or it may not be made available for use during any subsequent improvement works programme.

\section{ASBESTOS AND THE DECENT HOMES STANDARD}

SHPs are subject to either The Decent Homes Standard in England, ${ }^{3}$ the Welsh Housing Quality Standards ${ }^{4}$ or the Scottish Housing Quality Standards. ${ }^{5}$ Each of these standards make reference to the forthcoming change in the housing fitness standard, ie the introduction of the Housing Health \& Safety Rating System (HHSRS). ${ }^{6}$ It is implicit that when the HHSRS is introduced the relevant Decent Homes Standard ${ }^{7}$ will encompass the new HHSRS. 
As part of the Housing Act of $2004^{8}$ the HHSRS has been introduced as a replacement for the current Housing Fitness Standard. This new method of assessing housing fitness is likely to be introduced in November 2005. (The Office of the Deputy Prime Minister (private communication) states: 'We do not yet have a firm date for implementation of Part 1 of the Act. We hope this will be around November this year. Ahead of this we need to lay regulations and finalise enforcement guidance.')

The HHSRS is a risk-based approach to assessing housing quality with the emphasis on identifying those elements of housing that are potentially harmful to the health and/or safety of occupants or visitors. The HHSRS documents 29 hazards, of which one is asbestos. It is difficult to imagine how SHPs can confirm conformance with the standards without carrying out asbestos surveys of all their housing stock.

\section{Repair programmes}

\section{MAJOR REPAIRS PROGRAMMES}

Most RSLs now conduct major repair programmes that have been developed following stock condition surveys and the introduction of asset management software, making it even more likely that RSLs must now address the requirements of the Decent Homes Standard. Specifically, those RSLs that have been created to take over local authority stock are likely to have extensive programmes of work that are part of the stock transfer arrangements. In most of these cases, a full asbestos survey of the property concerned will be required prior to the work. Decisions will then need to be made in relation to how to deal with the ACMs discovered and this will need to be taken into account in the project budget. Careful consultation with tenants is important, as this is clearly an emotive topic.

Normally, a Type 3 survey will be commissioned for property that is going to be the subject of significant renovation works. This type of survey is intrusive and/or destructive. Because many of the RSL properties programmed for major repairs will be occupied during the survey and possibly during the works, a Type 3 survey may be impractical. In such cases, a Type 2 survey normally will be commissioned. The RSL must be aware of the limitations of this type of survey in relation to the proposed works. In such circumstances there are potential health and safety risks to tenants and maintenance workers. Where work is being carried out on the basis of a Type 2 survey, contractors should be trained to identify possible ACMs that may be uncovered during the course of the works and these should be sampled and analysed by a specialist prior to any work being commenced that may disturb them.

Many of the ACMs found in ex-council stock will be relatively easy to deal with and are best left in situ if in good condition. These include textured decorative coatings such as 'Artex' and vinyl floor tiles. Some products such as asbestos cement rainwater goods may be replaced at a reasonable cost as the work can be carried out with minimal disruption to tenants. This work is also unlicensed so that costs are not as high as for work that is required to be carried out by licensed contractors. RSLs should note that the work must be done to the required standards and all ACMs must be properly disposed of at a licensed tip. For unlicensed work, 
guidelines are detailed in the HSE publication ACOP L27: Work with Asbestos that Does Not Normally Require a Licence (HSE, 2002c).

\section{SUMMARY}

While most SHPs are getting to grips with meeting the requirements of Regulation 4 of CAWR 2002, as yet they may not be as advanced when dealing with domestic premises, ie tenants' homes. There was widespread use of ACMs in housing constructed in the last century. Tenants generally have quite a different view about issues outside their homes as opposed to those within them. Consequently, tenants will be much more interested in the possibility of asbestos being in their homes rather than it being outside them.

\section{References}

DETR and The Housing Corporation (1999) Dealing with Uncertainty. The Role of Warranties in Stock Transfers, DETR and The Housing Corporation, available at: www.housingcorplibrary. org.uk/housingcorp.nsf/AllDocuments/320993A03A2C247180256AB9003E2399/\$FILE/ uncertain.pdf.

Edmonds, D. and the Housing Quality Network Services for the Housing Corporation (2003) Inspection Uncovered, June, available at: www.housingcorplibrary.org.uk/housingcorp.nsf/ AllDocuments/20F275D938250A1480256D640056E3B5/\$FILE/RprsInspUnc.pdf.

HMSO (1994) Construction (Design \& Management) Regulations (CDM), available at: www. legislation.hmso.gov.uk/si/si1994/Uksi_19943140_en_1.htm.

HMSO (1998) Asbestos (Licensing) Regulations 1983 (as amended 1998), available at: www. legislation.hmso.gov.uk/si/si1998/19983233.htm.

HMSO (2004) Control of Asbestos at Work Regulations, available at: www.legislation.hmso.gov.uk/ si/si2002/20022675.htm.

HSE (1999) A Guide to the Asbestos (Licensing) Regulations 1983 (as amended), 2nd edition, L11, HSE.

HSE (2001a) Introduction to Asbestos Essentials - Comprehensive Guidance on Working with Asbestos in the Building Maintenance and Allied Trades, HSG213, HSE.

HSE (2001b) Surveying, Sampling and Assessment of Asbestos-containing Materials, MDHS 100, HSE, available at: www.hse.gov.uk/pubns/mdhs/pdfs/mdhs100.pdf.

HSE (2002a) The Management of Asbestos in Non-domestic Premises, Regulation 4 of the Control of Asbestos at Work Regulations 2002, ACOP L127, HSE.

HSE (2002b) A Comprehensive Guide to Managing Asbestos in Premises, HSG227, HSE.

HSE (2002c) Work with Asbestos that Does Not Normally Require a Licence, 4th edition, ACOP L27, HSE.

HSE (2003) Asbestos Essential Task Manual, HSG210, HSE.

Jude, D. (2005) 'Managing asbestos risk', Journal of Building Appraisal, 1(1), 34-46.

National Housing Federation (2004) 'Best practice asset management', 3(1), Spring, available at: www.housing.org.uk/library/viewfile. asp?fid $=2760$.

Welsh Assembly Government, Welsh Local Government Association \& Welsh Federation of Housing Associations (2004) Managing Asbestos in Social Housing, September.

\section{Notes}

(1) British Occupational Hygiene Society, Faculty of Occupational Hygiene, details available at: www.bohs.org/.

(2) Constructionline is owned and endorsed by the Department for Trade \& Industry, details are available at: www.constructionline.co.uk/default.asp.

(3) Decent Homes Standard Housing Corporation guidance is available at: www. housingcorplibrary.org.uk/housingcorp.nsf/AllDocuments/58C18158975404AF 80256D6C0036DAC4/\$FILE/decenthomesstandard.pdf. 
(4) Welsh Housing Quality Standards provide guidance for local authorities at: www.housing. wales.gov.uk/pdf.asp?a = e26 and guidance for RSLs at: www.housing.wales.gov.uk/pdf. asp?a $=\mathrm{e} 39$.

(5) Details of Scottish Housing Quality Standards are available at: www.scotland.gov.uk/ consultations/housing/msshletter.pdf.

(6) Information about the Housing Health \& Safety Rating System (HHSRS) is available from the ODPM at: www.odpm.gov.uk/stellent/groups/odpm_housing/ documents/page/ odpm_house_032782.pdf.

(7) Details of the Decent Homes Standard are available from the ODPM at: www.odpm.gov.uk/ stellent/groups/odpm_housing/documents/downloadable/ odpm_house_027345.pdf.

(8) Details of the Housing Act of 2004 are available from HMSO at: www.legislation.hmso.gov.uk/ acts/acts2004/20040034.htm. 